\title{
THE NEED TO CONSIDER FLEXURAL POST-CRACKING CREEP BEHAVIOR OF MACRO-SYNTHETIC FIBER REINFORCED CONCRETE
}

\author{
P. Pujadas ${ }^{\mathrm{a}}$, A. Blanco, S. Cavalaro ${ }^{\mathrm{a}}$, A. de la Fuente ${ }^{\mathrm{a}}$, A. Aguado ${ }^{\mathrm{a}}$
}

a Department of Civil and Environmental Engineering, Division of Geotechnical Engineering and Geosciences, School of Civil Engineering, Universitat Politècnica de Catalunya (UPC-Barcelona Tech), Jordi Girona 1-3, Building D2, Barcelona, Spain.

\begin{abstract}
The flexural creep of plastic fiber reinforced concrete (PFRC) is a controversial issue since significant doubts regarding the suitability of this type of fiber and its influence in the long-term behavior of the material still exist. The objective of this paper is to evaluate the post-cracking creep response of PFRC beams under flexural load in comparison with that of steel fiber reinforced concrete (SFRC) beams. The aim is to explore how the pre-crack opening and the environmental condition affect the long-term behavior of each material and identify differences. An experimental program was conducted with 30 concrete beams with dimension of 150x150x600 mm reinforced with plastic or steel fibers subjected to a 4-point bending creep test for 5 months under 2 environmental conditions. Results showed that the flexural creep coefficient of PFRC is 2 times bigger than that of SFRC. Despite that, the use of plastic fibers as reinforcement should not be rejected as long as the additional creep is considered in the design and the crack widths are limited to reduce the risk of tertiary creep.
\end{abstract}

Keywords: plastic fiber - synthetic fiber - FRC - four-point bending test - creep

\section{1-Introduction}

Fiber-reinforced concrete (FRC) is a competitive material for structural applications that demand a combination of moderate post-cracking tensile bearing capacity and high toughness [1-5]. Studies have shown that it is possible to achieve the desired structural performance by substituting either partial [6-9] or completely [10] the traditional reinforcement by fibers. Over the past decade, due to the heightened interest of the scientific community in macro-synthetic fibers [11], significant effort has gone into the development of new types of plastic fibers for structural applications [4, 12]. In this area, [13-15] demonstrated the feasibility of plastic fibers as the sole reinforcement (without rebars) in slabs under hyperstatic configurations, [16] showed that these fibers could be used as shear reinforcement in both wide-shallow and deep beams, and [17] experimentally tested their use as a reinforcement against localized splitting of precast tunnel segments.

Despite the advances in the field of concrete reinforced with plastic fibers, the use of steel fibers still predominates in elements with high structural responsibility. One of the most recurrent reasons for that choice is the uncertainty regarding the long-term performance of plastic-fiber reinforced concrete (PFRC). Under sustained load, concrete deformation gradually increases with time and may eventually be many times bigger than the initial value. This phenomenon - also known as creep - could affect negatively the structural performance of the elements in service. In certain situations, it may impair the serviceability of the structure and even lead to failure at a lower load than the static ultimate load [18-20]. From a design-oriented perspective, creep deformations should also be taken into account in the medium-to-long-term behavior of FRC [21, 22].

According to [18] and [20], creep of cracked FRC elements subjected to bending is the result of 3 components: concrete creep under compression, time-dependent debonding behavior at the fiber-matrix interface and fiber creep at a material level under tensile stress. In the case of Steel Fiber-Reinforced Concrete (SFRC), the creep deformation of the fibers is considered small so that the total creep is governed by the slow debond and pull-out of the fibers from the matrix [23, 24]. Conversely, in PFRC elements, the creep of the fiber may not be disregarded. This is a complex 
phenomenon that depends on the stress level, on intrinsic material properties (crystallinity and molecular orientation of the polymer) and on other external parameters (UV radiation, temperature and humidity) [25, 26]. Despite the relevance of the issue, information on flexural creep of PFRC is still limited [25], not being sufficiently addressed in design recommendations [22].

The objective of this paper is to evaluate the post-cracking creep response of PFRC beams under flexural load in comparison with that of SFRC beams. The aim is to explore how the initial crack opening and the environmental condition may affect the long term behavior of each material and to identify differences. For that purpose, an experimental program was conducted using 30 beams reinforced with either plastic or steel fibers. These beams were pre-cracked at 3 crack openings and underwent 4-point bending creep test for 5 months under 2 different environmental conditions.

The results obtained highlight differences in the behavior depending on the type of fiber, and contribute to enlarge the database available in the literature regarding the flexural creep of PFRC. Moreover, the conclusions derived from this study put forward the importance of limiting in the design the maximum crack width in order to reduce the risk of unacceptable deflections and failure of PFRC elements.

\section{2-Review of previous works}

Among the few studies about the uni-axial tensile creep of cracked FRC are those reported by [19] on steel fibers, by [18] and [27] on micro-synthetic fibers and by [22] on macro-synthetic fibers. Information on flexural creep behavior of FRC cracked sections in specimens [21, 28, 29] and in full-scale elements [30-32] is also available in the technical literature.

More recently, [24] studied the creep behavior of pre-cracked (widths ranging from 0.2 to 3.5 $\mathrm{mm}$ ) beams reinforced with steel fibers under a four-point bending configuration. The authors reported stable responses over 18 months for small pre-crack openings of up to $0.5 \mathrm{~mm}$, regardless of the load levels. However, for pre-crack openings larger than $0.5 \mathrm{~mm}$ and load ratios of 0.96 , relatively high crack-opening rates were observed, pointing towards possible initiation of creep failure. When the load was further increased, sudden failure occurred.

[33] and [34] tested 31 SFRC specimens under four-point bending in order to investigate the effects of various parameters on creep in cracked conditions. Through a multiple linear regression, the authors concluded that the load-ratio had an effect on the flexural creep response and that the extent of such effect depended on fiber slenderness and content.

[23] investigated the time-dependent behavior of cracked FRC round panels reinforced with either steel or synthetic fibers (considering 2 fiber types for each of them). The author reported that postcrack creep coefficients were insensitive to load ratio for the SFRC and for one of the two PFRC tested, while the creep coefficient of the second PFRC was sensitive to the load ratio.

Although studies are generally limited to a single pre-crack width, tests performed by [35], [24] and [33] had a pre-cracking range between 0.2 and $3.5 \mathrm{~mm}$. These works concur that crack-width directly affects the creep phenomenon.

\section{3-Experimental method}

In the present study, the time-dependent behavior under sustained load was investigated through 30 flexural 4-point bending tests on beams (with dimensions of 150x150x600 mm) reinforced with either plastic fibers (PF) or steel fibers (SF). The tests were performed in two environmental conditions (S1 and S2) over 5 months considering different pre-crack widths $(0.25 \mathrm{~mm}, 1.5 \mathrm{~mm}$ and $2.5 \mathrm{~mm}$ ). 


\section{1-Materials and mix design}

All concrete mixes were prepared in a 750-liter vertical-axis mixer. First, the dried components were mixed for one minute. Subsequently, the water was added and mixed for two minutes. Then, following the addition of the superplasticizer and the steel fibers, the concrete was mixed for two additional minutes. The total mixing time was 5-7 minutes. 4 batches of concrete specimens were produced: 2 with $5 \mathrm{~kg} / \mathrm{m}^{3}$ of PF and 2 with $40 \mathrm{~kg} / \mathrm{m}^{3}$ of SF. The specifications of each series of concrete mix are presented in Table 1 . The amount of superplasticizer and water were slightly adjusted to assure similar workability in all batches in order to favor similar fiber distribution in all specimens.

Table 1. Composition of the FRC mixture (in $\mathrm{kg} / \mathrm{m}^{3}$ )

\begin{tabular}{cccccc}
\hline \multirow{2}{*}{ Materials } & \multirow{2}{*}{ Characteristics } & \multicolumn{2}{c}{ PLASTIC FIBERS } & \multicolumn{2}{c}{ STEEL FIBERS } \\
\cline { 3 - 6 } & & S1/PF & S2/PF & S1/SF & S2/SF \\
\hline Gravel $(6 / 15 \mathrm{~mm})$ & Granite & 520 & 520 & 520 & 520 \\
Gravel $(2,5 / 6 \mathrm{~mm})$ & Granite & 400 & 400 & 400 & 400 \\
Sand $(0 / 3 \mathrm{~mm})$ & Granite & 500 & 500 & 500 & 510 \\
Cement & CEM I 52,5 R & 400 & 400 & 400 & 350 \\
Filler & Marble dust & 260 & 260 & 260 & 300 \\
Water & - & 170 & 178 & 168 & 178 \\
Superplasticizer & Adva® Flow 400 & 12 & 12 & 12 & 12 \\
Fibers & PF/SF & $5(\mathrm{PF})$ & $5(\mathrm{PF})$ & $40(\mathrm{SF})$ & $40(\mathrm{SF})$ \\
\hline
\end{tabular}

The plastic macro-fibers (PF) used in the tests were straight strips of polyolefin with rectangular cross-sections and a continuously embossed surface texture to improve adherence. The lowcarbon steel fibers (SF) had circular cross-sections and hooked ends, being gathered into bundles with water-soluble glue. Further details about the characteristics of both fibers are presented in Table 2.

Table 2 - Fiber characteristics provided by the manufacturers

\begin{tabular}{cccc}
\hline Characteristic & Unity & PF & SF \\
\hline Length $(L)$ & {$[\mathrm{mm}]$} & 48 & 50 \\
Equivalent Diameter $(d)$ & {$[\mathrm{mm}]$} & - & 0.62 \\
Aspect ratio $(L / d)$ & {$[-]$} & 44 & 83 \\
Tensile strength $(f y)$ & {$[\mathrm{MPa}]$} & 550 & 1270 \\
Modulus of elasticity $(E)$ & {$[\mathrm{GPa}]$} & 10 & 210 \\
Number of fibers per kg & {$[$ fibers] } & $>35000$ & 8100 \\
\hline
\end{tabular}

The following specimens were cast for each batch: 3 prismatic beams $(150 \times 150 \times 600 \mathrm{~mm})$ for the creep test, 3 prismatic beams $(150 \times 150 \times 600 \mathrm{~mm})$ for flexural strength tests according with EN 14651:2005, 3 cylindrical samples $(150 \times 300 \mathrm{~mm}$ ) for compressive strength tests according with UNE 83507:2004, and 3 cylindrical samples $(150 \times 300 \mathrm{~mm})$ to test the modulus of elasticity in accordance with UNE 83316:1996. All of them were externally vibrated over a vibrating table at $3000 \mathrm{rpm}$ for approximately 10 seconds. They were removed from the molds after 24 hours of casting and moist cured under a plastic sheet for approximately one week. After that, they were transported from the ESCOFET S.A. facilities to the Luis Agulló Laboratory of Structural Technology at the Universitat Politècnica de Catalunya (Polytechnic University of Catalonia), where they were kept in a curing room at $20 \pm 2^{\circ} \mathrm{C}$ and $95 \%$ of relative humidity.

Table 3 shows the average compressive strength $\left(f_{\mathrm{cm}}\right)$, average modulus of elasticity $\left(\mathrm{E}_{\mathrm{cm}}\right)$, limit of proportionality $\left(f_{L}\right)$ and the residual flexural tensile strengths $\left(f_{R 1}, f_{R 2}, f_{R 3}\right.$ and $\left.f_{R 4}\right)$ corresponding to CMODs of $0.05 \mathrm{~mm}, 0.50 \mathrm{~mm}, 1.50 \mathrm{~mm}, 2.50 \mathrm{~mm}$ and $3.50 \mathrm{~mm}$, respectively. 
Table 3 - Characterization of the FRC at 28 days

\begin{tabular}{|c|c|c|c|c|c|c|c|c|}
\hline & \multicolumn{2}{|c|}{ S1/PF } & \multicolumn{2}{|c|}{ S2/PF } & \multicolumn{2}{|c|}{ S1/SF } & \multicolumn{2}{|c|}{ S2/SF } \\
\hline & $\begin{array}{c}\text { Average } \\
\text { [MPa] }\end{array}$ & $\begin{array}{c}\mathrm{CV} \\
\%\end{array}$ & $\begin{array}{c}\text { Average } \\
{[\mathrm{MPa}]}\end{array}$ & $\begin{array}{c}\mathrm{CV} \\
\%\end{array}$ & $\begin{array}{c}\text { Average } \\
\text { [MPa] }\end{array}$ & $\begin{array}{c}\text { CV } \\
\%\end{array}$ & $\begin{array}{c}\text { Average } \\
{[\mathrm{MPa}]}\end{array}$ & $\begin{array}{l}\text { CV } \\
\%\end{array}$ \\
\hline$E_{c m}$ & 31150 & 1.69 & - & - & 31597 & 1.08 & 30160 & 2.20 \\
\hline$f_{c m}$ & 52.15 & 1.52 & 48.89 & 1.57 & 54.30 & 1.51 & 46.77 & 2.54 \\
\hline$f_{L}$ & 4.61 & 2.19 & 4.22 & 2.66 & 3.73 & 8.57 & 3.76 & 7.96 \\
\hline$f_{R, 1}$ & 2.01 & 22.30 & 2.38 & 15.54 & 4.62 & 12.15 & 3.75 & 22.29 \\
\hline$f_{R, 2}$ & 2.25 & 28.53 & 2.93 & 20.89 & 5.09 & 13.77 & 4.24 & 17.91 \\
\hline$f_{R, 3}$ & 2.46 & 26.84 & 3.32 & 24.15 & 5.10 & 15.91 & 4.30 & 15.88 \\
\hline$f_{R, 4}$ & 2.48 & 23.47 & 3.49 & 27.40 & 4.87 & 14.08 & 4.17 & 15.68 \\
\hline
\end{tabular}

\section{2-Test procedure}

The specimens were subjected to two different loading phases schematized in Figure 1. Phase 1 comprised the pre-cracking of the beams until a nominal crack width, whereas Phase 2 included the creep test.

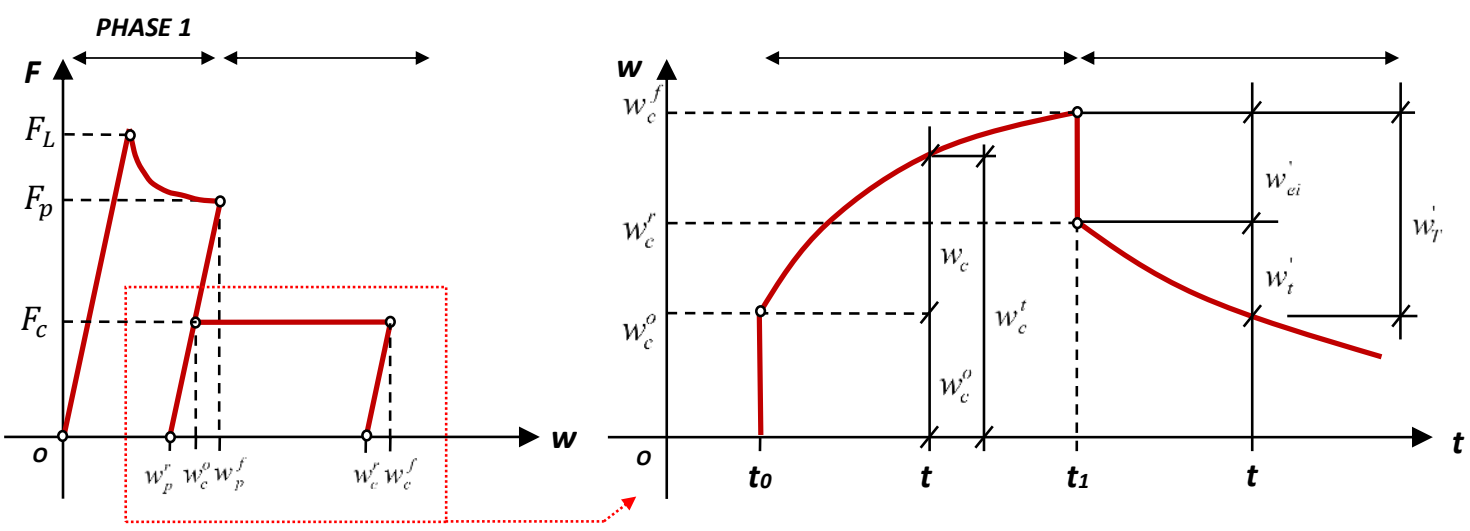

Figure 1 - Diagram of the complete test procedure

In Phase 1, specimens with a $25 \mathrm{~mm}$ notch were placed in a closed-loop servo-hydraulic press supported by 2 rollers $450 \mathrm{~mm}$ apart from each other. Then, they were subjected to a 4-point bending test, using crack-mouth opening displacement (CMOD) as the control signal. In addition to the clip gauge placed at the bottom of the beam, crack-opening displacement $\left(w_{p}^{f}\right)$ was monitored by a linear variable differential transducer (LVDT) attached to the lateral side of the specimen, $12 \mathrm{~mm}$ above the lower surface (see Fig. 2b).

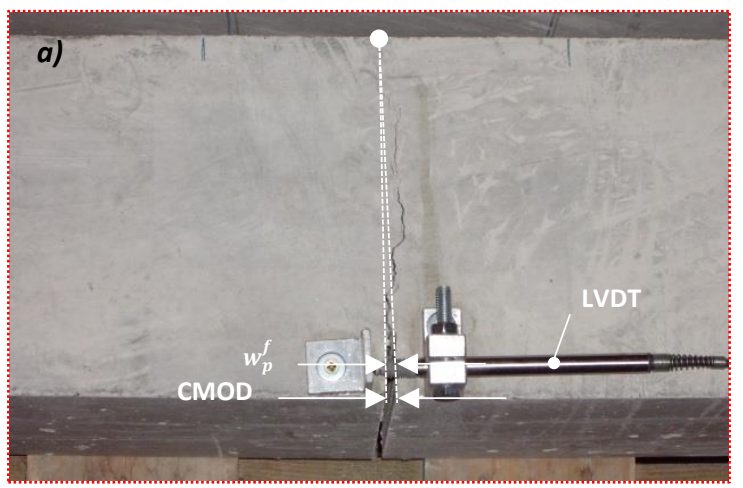

b)

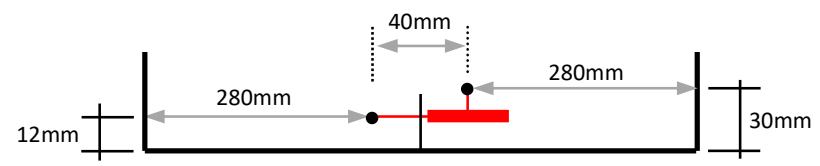

Figure 2 - Pre-cracking of the beams in Phase 1 (a) and detail of the position of the LVDT at the lateral side of the beam $(b)$ 
To obtain different pre-cracking openings, the process was interrupted at $w_{p}^{f}$ of approximately $0.25 \mathrm{~mm}, 1.50 \mathrm{~mm}$ and $2.50 \mathrm{~mm}$. Table 4 shows the $w_{p}^{f}$ of each beam that was tested. For the pre-cracking and the creep test, specimens were supported and loaded on the two parallel sides that were in contact with the lateral sides of the mold during the casting procedure.

Table 4. - Summary of loading conditions and pre-crack width

\begin{tabular}{|c|c|c|c|c|c|c|c|}
\hline \multirow[b]{2}{*}{ S1 } & \multirow[b]{2}{*}{$\mathbf{P F}$} & \multirow{2}{*}{$\begin{array}{c}\text { SPECIMENS } \\
\text { S1.PF_0.25P1 }\end{array}$} & \multirow{2}{*}{$\begin{array}{c}t \\
\text { [days] } \\
151\end{array}$} & \multicolumn{2}{|c|}{$\begin{array}{c}w_{p}^{f} \\
{[m m]}\end{array}$} & \multirow{2}{*}{$\begin{array}{c}\begin{array}{c}\boldsymbol{F}_{\boldsymbol{c}} \\
{[\boldsymbol{k N}]}\end{array} \\
6.8\end{array}$} & \multirow{2}{*}{$\begin{array}{c}\bar{\xi}=\boldsymbol{F}_{\boldsymbol{c}} / \boldsymbol{F}_{\boldsymbol{p}} \\
{[\%]} \\
48.9\end{array}$} \\
\hline & & & & \multirow[t]{5}{*}{0.25} & 0.244 & & \\
\hline & & S1.PF_0.25P2 & 151 & & 0.232 & 7.1 & 58.2 \\
\hline & & S1.PF_0.25P3 & 151 & & 0.236 & 10.1 & 69.1 \\
\hline & & S1.PF $0.25 P 4$ & 151 & & 0.230 & 9.4 & 57.3 \\
\hline & & S1.PF_0.25P5 & 151 & & 0.2516 & 9.8 & 60.5 \\
\hline & & S1.PF_1.50P6 & 151 & \multirow[t]{2}{*}{1.50} & 1.507 & 9.1 & 50.0 \\
\hline & & $S 1 . P F_{-} 1.50 P 7$ & 151 & & 1.507 & 6.5 & 50.4 \\
\hline & & S1.PF_2.50P8 & 151 & \multirow{2}{*}{2.50} & 2.536 & 9.5 & 54.0 \\
\hline & & S1.PF_2.50P9 & 151 & & 2.532 & 8.8 & 48.6 \\
\hline & \multirow[t]{6}{*}{ SF } & S1.SF_0.25P1 & 151 & \multirow[t]{3}{*}{0.25} & 0.336 & 14.5 & 53.9 \\
\hline & & S1.SF_0.25P2 & 151 & & 0.332 & 14.6 & 61.6 \\
\hline & & S1.SF $0.25 P 3$ & 151 & & 0.363 & 14.7 & 69.8 \\
\hline & & S1.SF_1.50P4 & 151 & 1.50 & 1.578 & 16.3 & 52.9 \\
\hline & & S1.SF_2.50P5 & 151 & \multirow[t]{2}{*}{2.50} & 2.746 & 16.2 & 49.5 \\
\hline & & S1.SF_2.50P6 & 151 & & 2.825 & 16.2 & 47.5 \\
\hline \multirow[t]{15}{*}{ S2 } & \multirow[t]{6}{*}{$\mathbf{P F}$} & $S 2 . P F_{-} 0.25 P 1$ & 98 & \multirow[t]{4}{*}{0.25} & 0.251 & 6.6 & 48.9 \\
\hline & & $\begin{array}{l}S 2 . P F \\
0.25 P 2\end{array}$ & 98 & & 0.266 & 5.6 & 48.3 \\
\hline & & $S 2 . P F \_0.25 P 3$ & 98 & & 0.244 & 5.3 & 48.6 \\
\hline & & $S 2 . P F=0.25 P 4$ & 98 & & 0.260 & 6.3 & 52.6 \\
\hline & & $S 2 . P F=1.50 P 5$ & 98 & 1.50 & 1.499 & 5.0 & 43.1 \\
\hline & & $S 2 . P F \_2.50 P 6$ & 108 & 2.50 & 2.498 & 6.0 & 49.3 \\
\hline & \multirow[t]{9}{*}{ SF } & S2.SF_0.25Pl & 98 & \multirow[t]{6}{*}{0.25} & 0.257 & 9.1 & 47.0 \\
\hline & & S2.SF_0.25P2 & 98 & & 0.252 & 10.4 & 62.2 \\
\hline & & S2.SF_0.25P3 & 98 & & 0.202 & 10.5 & 52.3 \\
\hline & & S2.SF_0.25P4 & 98 & & 0.253 & 10.4 & 52.3 \\
\hline & & S2.SF_0.25P5 & 98 & & 0.251 & 7.1 & 46.5 \\
\hline & & S2.SF_0.25P6 & 98 & & 0.252 & 7.1 & 53.7 \\
\hline & & $S 2 . S F_{-} 1.50 P 7$ & 98 & \multirow[t]{2}{*}{1.50} & 1.502 & 7.1 & 46.8 \\
\hline & & $S 2 . S F_{-}^{-} 1.50 P 8$ & 98 & & 1.500 & 9.1 & 48.0 \\
\hline & & $S 2 . S F \_2.50 P 9$ & 98 & 2.50 & 2.501 & 9.0 & 37.1 \\
\hline
\end{tabular}

The pre-cracked beams were unloaded and immediately placed in a creep frame to initiate Phase 2 (creep test). The design of the set up for the flexural creep test was based on previous work by [36], being identical to those from [24], [33] and [34]. As depicted in Fig. 3, a predefined weight is placed over a lever arm that pivots on a fulcrum and transfers the load to the beams by means of two threaded steel bars on both sides of the beams.Each steel frame allowed the simultaneous test of 3 beams arranged vertically one over the other in a column. A 4-point bending test configuration was used with steel rollers to transmit the load between beams of the same column (see Fig. 3). The support over the uppermost specimens acted simultaneously as the loading points on the specimens immediately below (for which the intermediate specimen in each frame was turned). The lateral LVDT used to measure the $w_{p}^{f}$ during the pre-cracking stage remained alongside the beam and was used to register the crack-opening evolution during the creep test $\left(w_{c}^{t}\right)$. The assessment of the $w_{c}^{t}$ was conducted as proposed in [21] and [24]

The load level (Fc) used for the creep test was a percentage $\xi$ (between $50 \%$ and $60 \%$, see Table 4) of the load registered in the pre-cracking phase (Fp). The self-weight of the beams (G) was considered for the estimation of the load level, which could not be exactly identical for the beams of the same column due to the difference in pre-cracking load and the influence of the self-weight. Load cells were employed to control the load of each frame throughout the creep test. 

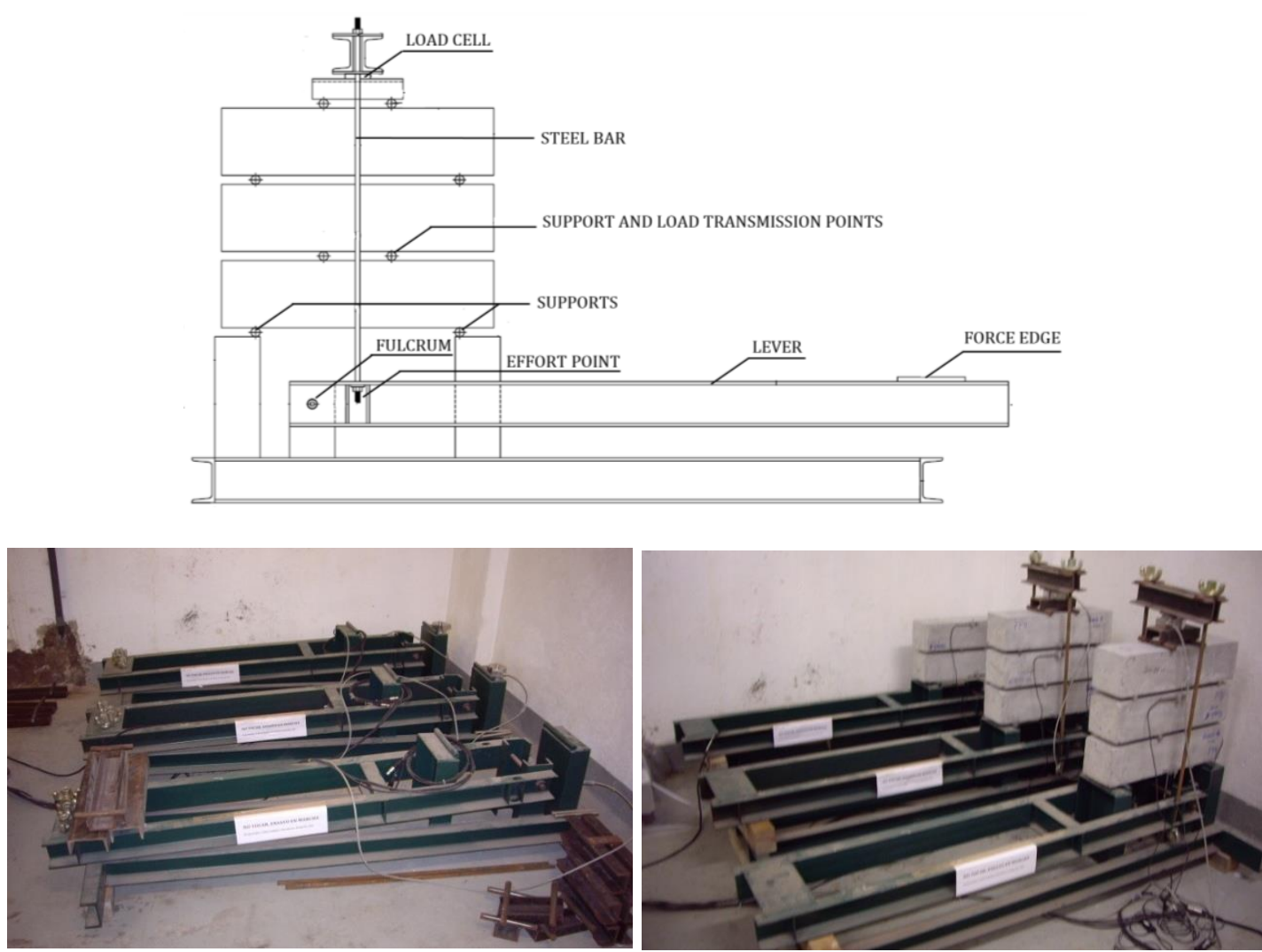

Figure 3 - Side view of the frame for the creep test (a), creep frame before (b) and after (c) loading.

During the creep test, 15 beams were kept in a climate-controlled room under relatively constant conditions (environment S1). The rest of the beams were kept under laboratory conditions without any control of the temperature and the humidity (environment S2). Fig. 4 shows the temperature and humidity measured during the creep tests of beams subjected to S1 and S2.
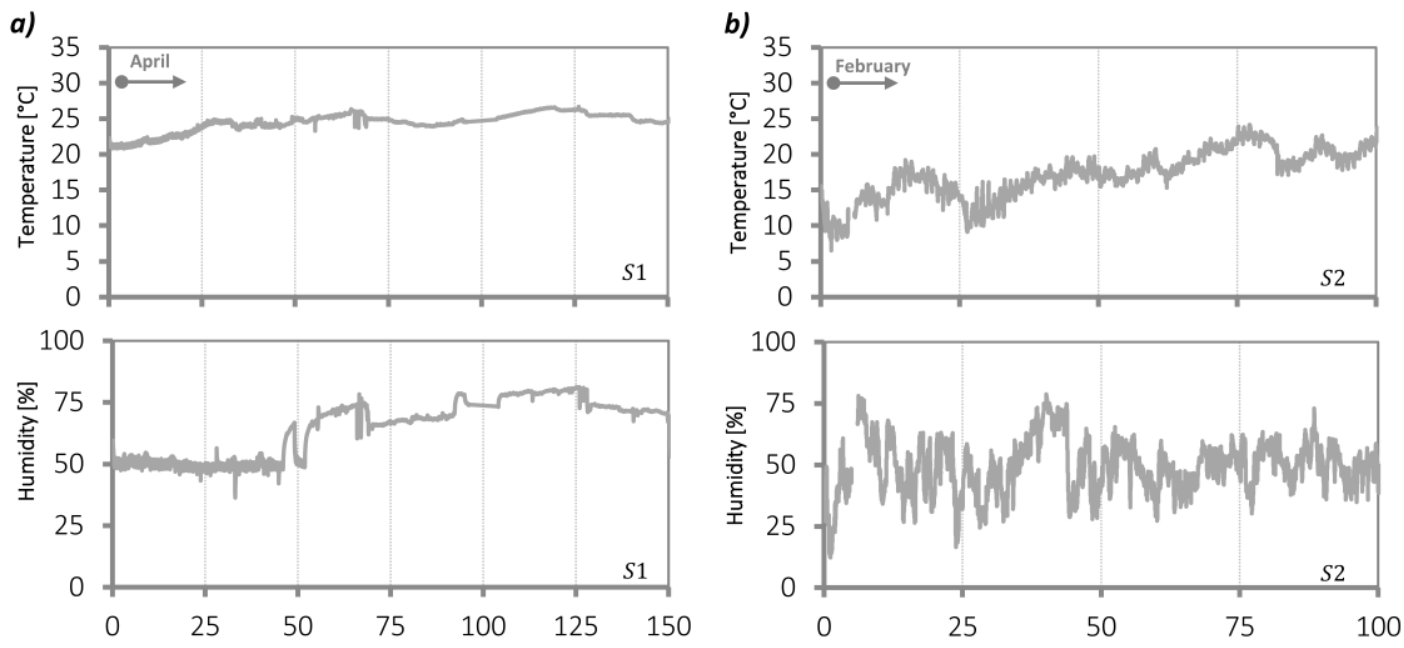

Figure 4 - Humidity and temperature throughout creep tests for environment $S 1$ (a) and S2 (b)

The total duration of the long-term loading had to be chosen so that the stabilization of the timedependent crack widths would be reached. When loading SFRC specimens at 50\% of their capacity at the pre-cracking level, [24] observed a slight increase of crack width in early ages, followed by a stabilization. [37] and [38] reported stabilization after 12 weeks (84 days). On the contrary, [39] and [40] considered that the time-dependent deformations increased continuously 
up to failure due to fiber debonding and pull-out. Consequently, they rejected the possibility of reaching a stabilized time-dependent crack-width. Likewise, [41] found no stabilization of the crack width after 3-months (84 days) of loading and suggested to extend the test for a longer period of time. Considering the aforementioned, in the present experimental program, the specimens were loaded at an age $t_{0}$ of 40 days and the duration of the sustained load stage was extended to 151 days (5 months) and 98 days (3.5 months) for environments S1 and S2, respectively. After that, specimens were unloaded.

The nomenclature used here to refer to each beam includes the environment (S1 or S2), a back slash, the type of fiber (PF or SF), an underline, the value of the nominal $w_{p}^{f}(0.25 \mathrm{~mm}, 1.50 \mathrm{~mm}$ or $2.50 \mathrm{~mm}$ ), and the reference of the specimen. For example, S1/PF_0.25P1 indicates the specimen P1 with plastic fiber, which had been pre-cracked to a nominal opening of $0.25 \mathrm{~mm}$ and subjected to the creep test at environment S1.

In order to maximize the observations derived from this study and the comparison of both types of fibers, the number of beams tested for each combination of variables was optimized taking into account the conditions considered more representative of reality (see Table 4). With that in mind, a bigger number of specimens were test for the pre-crack opening of $0.25 \mathrm{~mm}$ since it is considered more representative of SLS. Therefore, for this pre-crack opening, 5 PFRC beams were tested in environment S1, 4 PFRC beams were tested in environment S2, 3 SFRC beams were tested in environment S1 and 6 SFRC beams were tested in environment S2. Consequently, a smaller number of elements were available for testing with pre-crack openings of $1.50 \mathrm{~mm}$ and $2.50 \mathrm{~mm}$ (6 PFRC and 6 SFRC, in total).

\section{4-Experimental results and discussion}

\section{1-Primary and secondary creep in environment $S 1$}

Fig. 5 presents the increment of crack opening $\left(\Delta w_{c}^{t}\right)$ over time for beams in the environment S1 with $w_{p}^{f}$ of $0.25 \mathrm{~mm}$ and $1.50 \mathrm{~mm}$. The $\Delta w_{c}^{t}$ was calculated as the difference between the crack opening at a certain time and that measured at the beginning of the creep test immediately after applying the load.
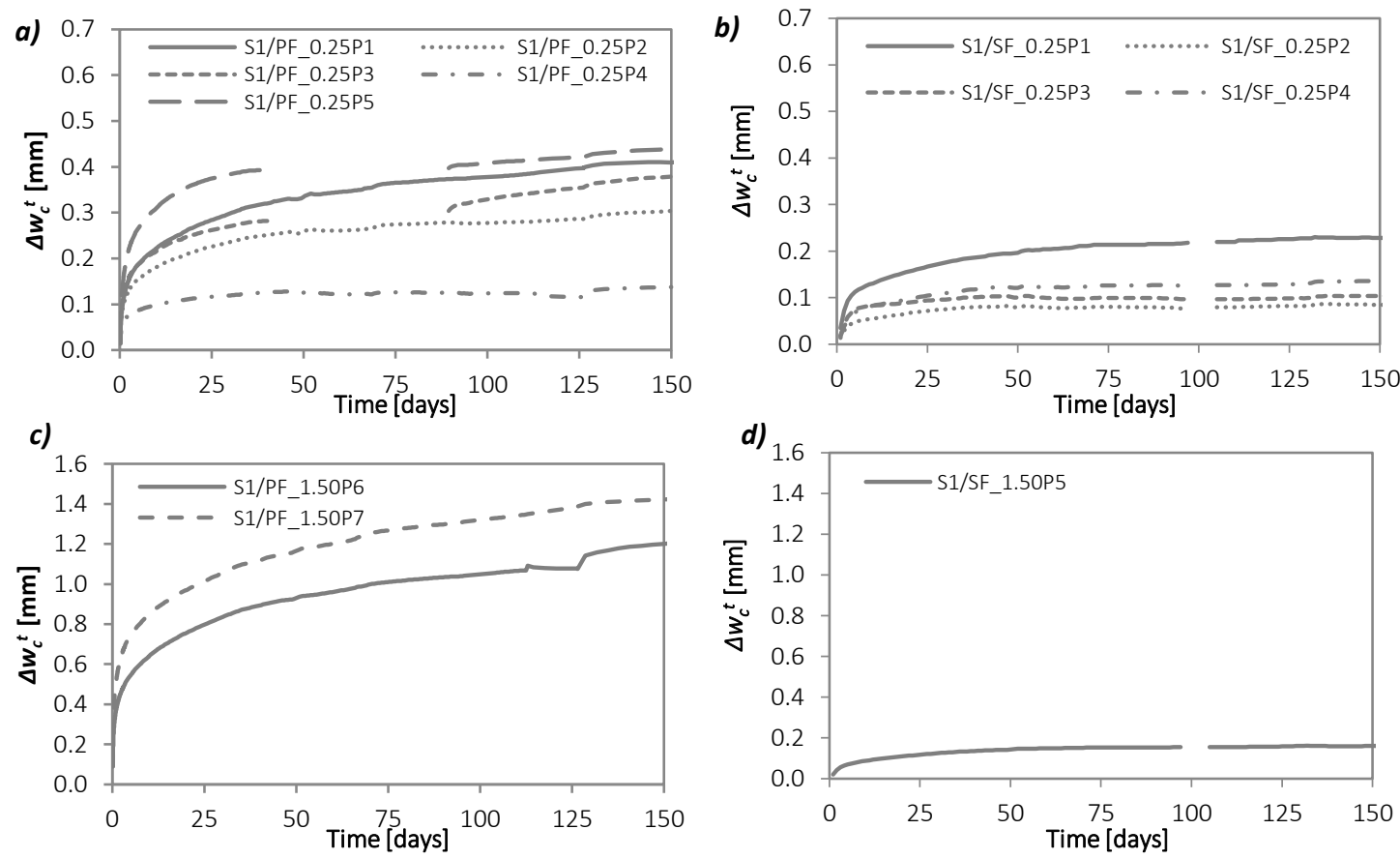

Figure 5 - Evolution of $\Delta w_{c}^{t}$ over time for specimens with $w_{p}^{f}$ of $0.25 \mathrm{~mm}$ and $1.50 \mathrm{~mm}$ in environment S1 
After 150 days of loading, the $\Delta w_{c}^{t}$ values registered by the specimens pre-cracked at a $w_{p}^{f}$ of $0.25 \mathrm{~mm}$ in environment $\mathrm{S} 1$ varied between 0.30 and $0.45 \mathrm{~mm}$ for PFRC (see Fig. 5a) and between 0.08 and $0.13 \mathrm{~mm}$ for SFRC (see Fig. 5b). An unusual behavior was recorded for specimen S1/PF_0.25P4 that showed a final $\Delta w_{c}^{t}$ between 3 and 4 times smaller than the other beams with the same material and $w_{p}^{f}$. Specimens with a $w_{p}^{f}$ of $1.50 \mathrm{~mm}$ reached values of $\Delta w_{c}^{t}$ between 1.20 and $1.40 \mathrm{~mm}$ for PF (see Fig. 5c), while SF reached only $0.15 \mathrm{~mm}$ (see Fig. 5d).

All results suggest that the increment of $\Delta w_{c}^{t}$ due to creep of PFRC was several times bigger than that of SFRC. Such difference can be attributed to a higher damage induced to the fiber-matrix interface in the PFRC for a certain pre-crack opening, which would favor the long-term deboning under sustained load and the own creep of the plastic fiber at an individual level.

Curves in Fig. 5 indicate that the behavior of both PFRC and FRC beams are governed by primary and secondary creep [29]. The rate of increase of $\Delta w_{c}^{t}$ was higher in the first days and depleted with time (primary creep) reaching an approximately constant rate of increase that was maintained at later ages (secondary creep). On average, about $50 \%$ of $\Delta w_{c}^{t}$ at 150 days happened in the first 5 days of testing, $70 \%$ in the first 30 days and $90 \%$ in the first 90 days.

This behavior is easily identified in Fig. 6, which shows the evolution of the creep rate for beams @1 1/PF_0.25P1 and S1/PF_1.50P7, which are repregsentative of those with $w_{p}^{f}$ of $0.25 \mathrm{~mm}$ and 1.50 $\mathrm{mm}$, respectively. The onset of secondary creep in the environment $\mathrm{S} 1$ took place from 25 to 50 days after application of the load. Specimens with $w_{p}^{f}$ of $1.50 \mathrm{~mm}$ displayed higher secondary creep in comparison with equivalent ones with $w_{p}^{f}$ of $0.25 \mathrm{~mm}$. This trend was maintained for PFRC and SFRC.
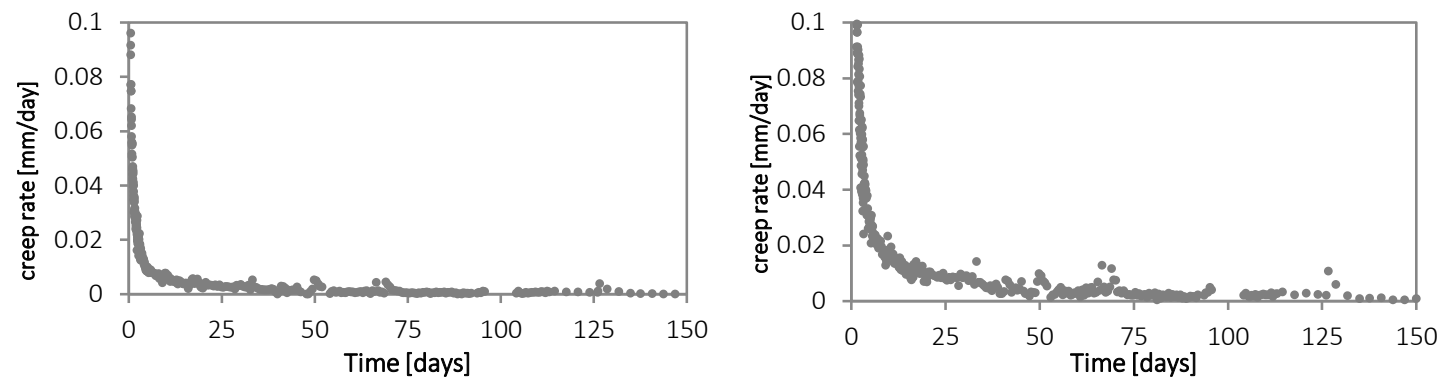

Figure 6-Evolution of creep rate for S1/PF1_0.25P1 (a) and S1/PF1_1.50P7 (b)

\section{2-Primary and secondary creep in environment $\mathrm{S} 2$}

Fig. 7 shows the evolution of $\Delta w_{c}^{t}$ for beams in environment S2. In the case of beams pre-cracked with $w_{p}^{f}$ of $0.25 \mathrm{~mm}$, the $\Delta w_{c}^{t}$ after 90 days of testing varied between 0.30 and $0.45 \mathrm{~mm}$ for the PFRC (see Fig. 7a) and between 0.04 and 0.14 for the SFRC (Fig. 7b). The PFRC beams precracked with a $w_{p}^{f}$ of $1.50 \mathrm{~mm}$ reached a $\Delta w_{c}^{t}$ of approximately $0.90 \mathrm{~mm}$ (see Fig. 7c), in contrast with the maximum value of $0.14 \mathrm{~mm}$ found for the equivalent beams with steel fibers (Fig. 7d). Again, PFRC beams presented considerably bigger $\Delta w_{c}^{t}$ than equivalent beams with SFRC. 

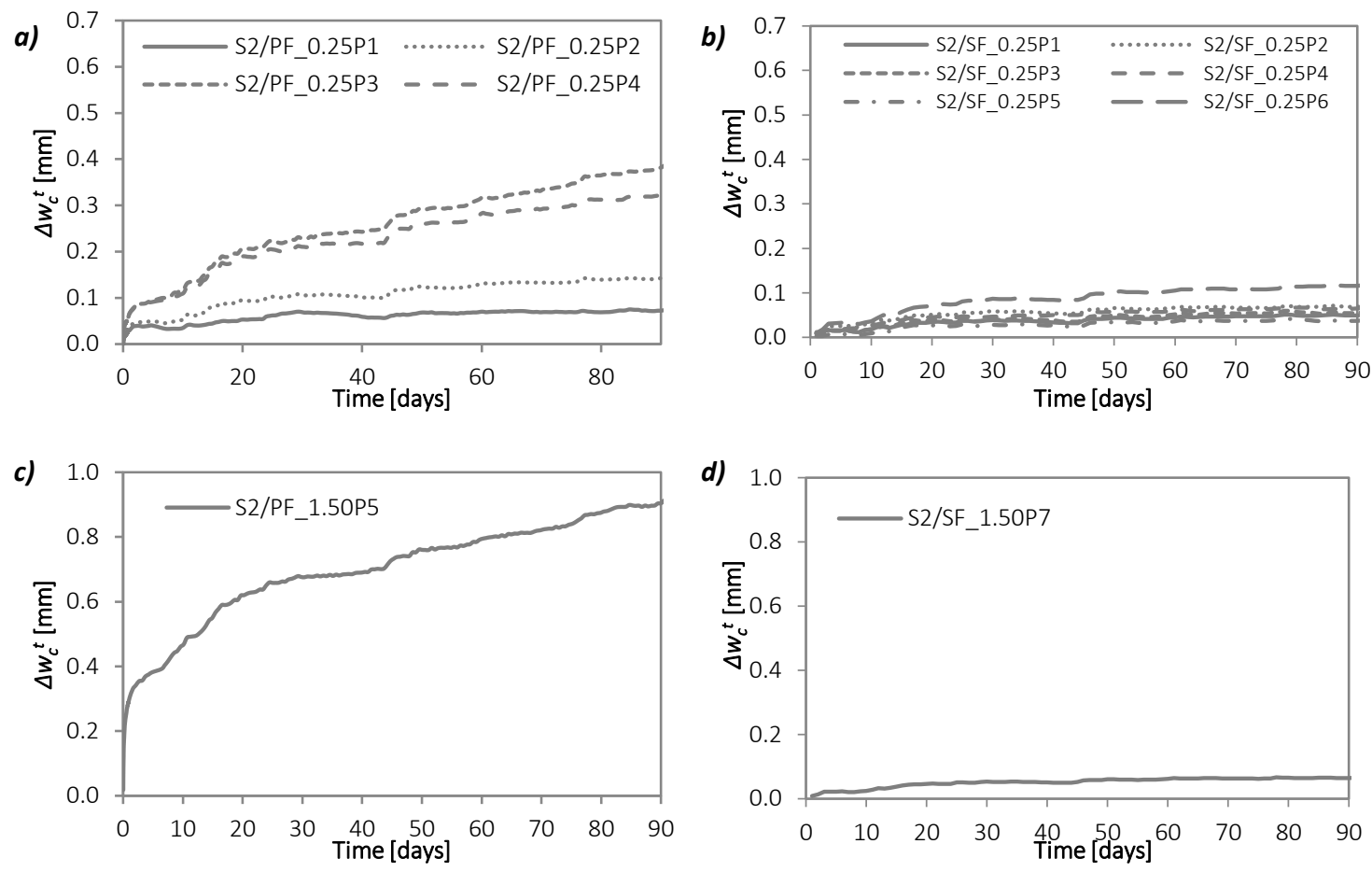

Figure 7 - Evolution of $\Delta w_{c}^{t}$ over time for specimens with $w_{p}^{f}$ of $0.25 \mathrm{~mm}$ and $1.50 \mathrm{~mm}$ in environment $S 2$

The trend of the creep curves obtained in environment S2 differs considerably from those found in environment $\mathrm{S} 1$. A close comparison of equivalent specimens (S1.PF_0.25P2 and S2.PF_0.25P4) is presented in Fig. 8. The change between primary and secondary creep is not as evident in S2 as it is in S1. In fact, the initial creep rate increased monotonously over time in S2, while it stabilized within several days in the environment S1. Despite that, the initial rate of increment of $\Delta w_{c}^{t}$ for S1 was larger than that for environment S2. Consequently, until around 8 days after the beginning of the test, the $\Delta w_{c}^{t}$ found in S2 was smaller than that observed in S1 for equivalent specimens. It was only after 8 days when the $\Delta w_{c}^{t}$ in S2 exceeded that measured in S1. Such observations are consistent with the results presented by [42] in tension creep tests and [43] in flexural creep tests of conventional concrete, but has not been reported in the case of compression creep tests.
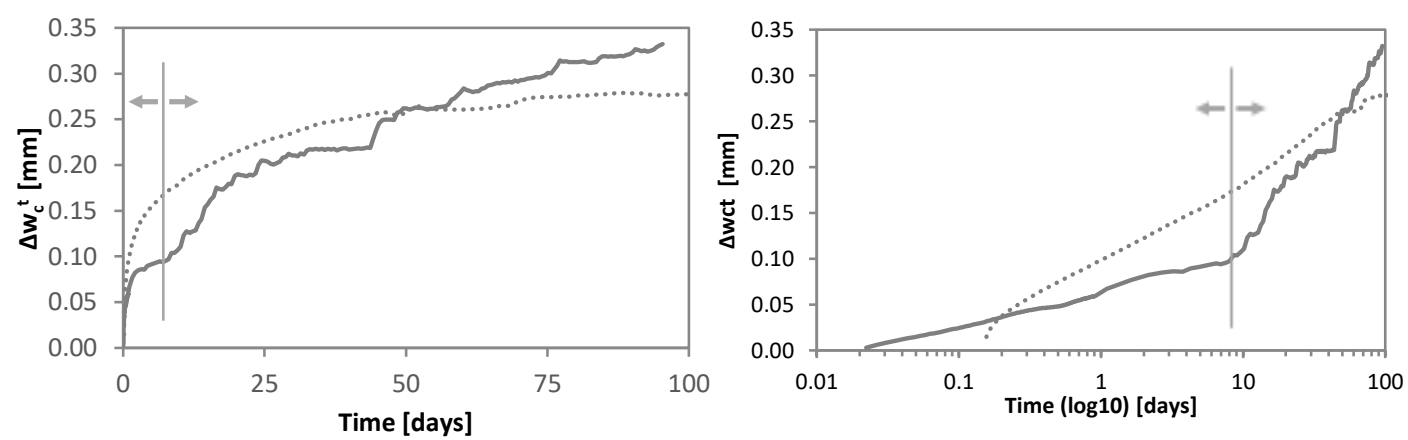

Figure 8 - Comparison of the evolution of $\Delta w_{c}^{t}$ for $S 1 / P F \_0.25 P 2$ and S2/PF_0.25P4

In order to explain the differences between $\mathrm{S} 1$ and $\mathrm{S} 2$, it is important to consider the changes in the environmental conditions experienced by the beams throughout the experimental program. In the case of S1, specimens were stored prior to pre-cracking and after pre-cracking in the climatic chamber. However, in the case of S2, specimens were kept in the climatic chamber before precracking and maintained in laboratory conditions during the creep test. Consequently, specimens 
tested in S1 maintained similar temperature and humidity conditions over time, whereas specimens in S2 had to reach equilibrium with the environment during the creep test.

This may have contributed to two different physical mechanisms that explain the behavior of specimens in S2: a creep-induced shrinkage [42] observed in the initial days and a shrinkageinduced creep that arises at later ages. In the beginning of the test, the increase of the crack opening caused by the creep phenomenon would be partially compensated by the drying shrinkage of the specimens under S2. Consequently, smaller increases of the crack opening were initially measured for beams subjected to S2. As equilibrium with the environment is reached, the influence of shrinkage in the crack opening is eclipsed. This, combined with the bigger likelihood of microcracking due to differential shrinkage strain, led to higher crack openings in the long term for beams at environment $\mathrm{S} 2$.

The influence of both mechanisms is evident in Fig. 9, which shows the evolution of $\Delta w_{c}^{t}$ in a logarithmic scale for beams subjected to S2. Beams under S2 showed a change in the trend approximately at 8 days of testing, highlighting the possible influence of the humidity equilibrium with the environment.

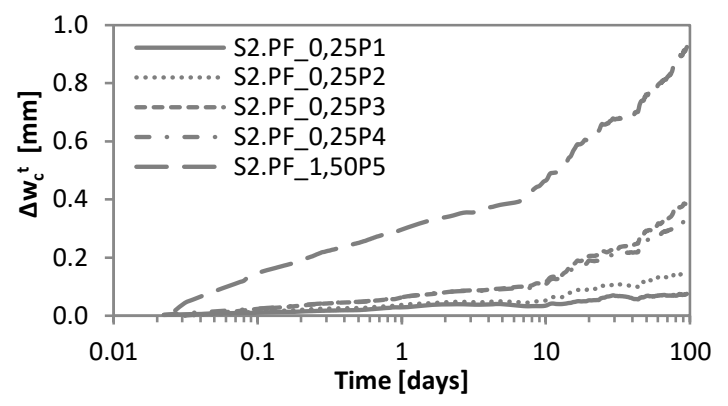

Figure 9 - Evolution of $\Delta w_{c}^{t}$ in logarithmic scale for specimens with $w_{p}^{f}$ of $0.25 \mathrm{~mm}$ and $1.50 \mathrm{~mm}$ subjected to environment $S 2$

\section{3-Tertiary creep}

During the test, none of the beams pre-cracked at $w_{p}^{f}$ of $0.25 \mathrm{~mm}$ and $1.5 \mathrm{~mm}$ presented tertiary creep [29], characterized by an acceleration of creep rate that leads to failure. Such tertiary creep was only observed in PFRC beams pre-cracked at $w_{p}^{f}$ of $2.50 \mathrm{~mm}$, as shown in Fig. 10a and 10b.

The damage induced by the advanced pre-cracking $\left(w_{p}^{f}\right.$ of $\left.2.50 \mathrm{~mm}\right)$ together with the load level applied during the test ( $\xi$ around 0.50 ) contributed to the debilitation of the fiber-matrix bond. The additional crack opening produced by the primary and the secondary creep intensified this debilitation, favoring the debonding and pull-out of plastic fibers. Consequently, the reinforcing action of fibers in the zone with higher tensile strength was progressively depleted, which caused additional increases of the crack opening. This led to an acceleration on the rate of increase of $\Delta w_{c}^{f}$ until the failure shown in Fig. 11 happened as the neutral axis reaches the limit of the cross section. In this experimental program, failure took place after 41, 112 and 108 days of loading for S1.PF_2.50P8 $(\xi=0.54)$, S1.PF_2.50P9 $(\xi=0.48)$ and S2.PF_2.50P6 $(\xi=0.49)$, respectively.

In contrast, none of the beams with SFRC and $w_{p}^{f}$ of $2.50 \mathrm{~mm}$ were affected by tertiary creep (see Fig 10c and 10d). The values of $\Delta w_{c}^{t}$ recorded at the end of the creep test in those beams ranged between 0.1 and $0.2 \mathrm{~mm}$, which were even lower than the obtained for beams with PFRC and $w_{p}^{f}$ of $0.25 \mathrm{~mm}$. To this date, only [24] has reported tertiary creep on SFRC for load ratios of around 0.96 . 

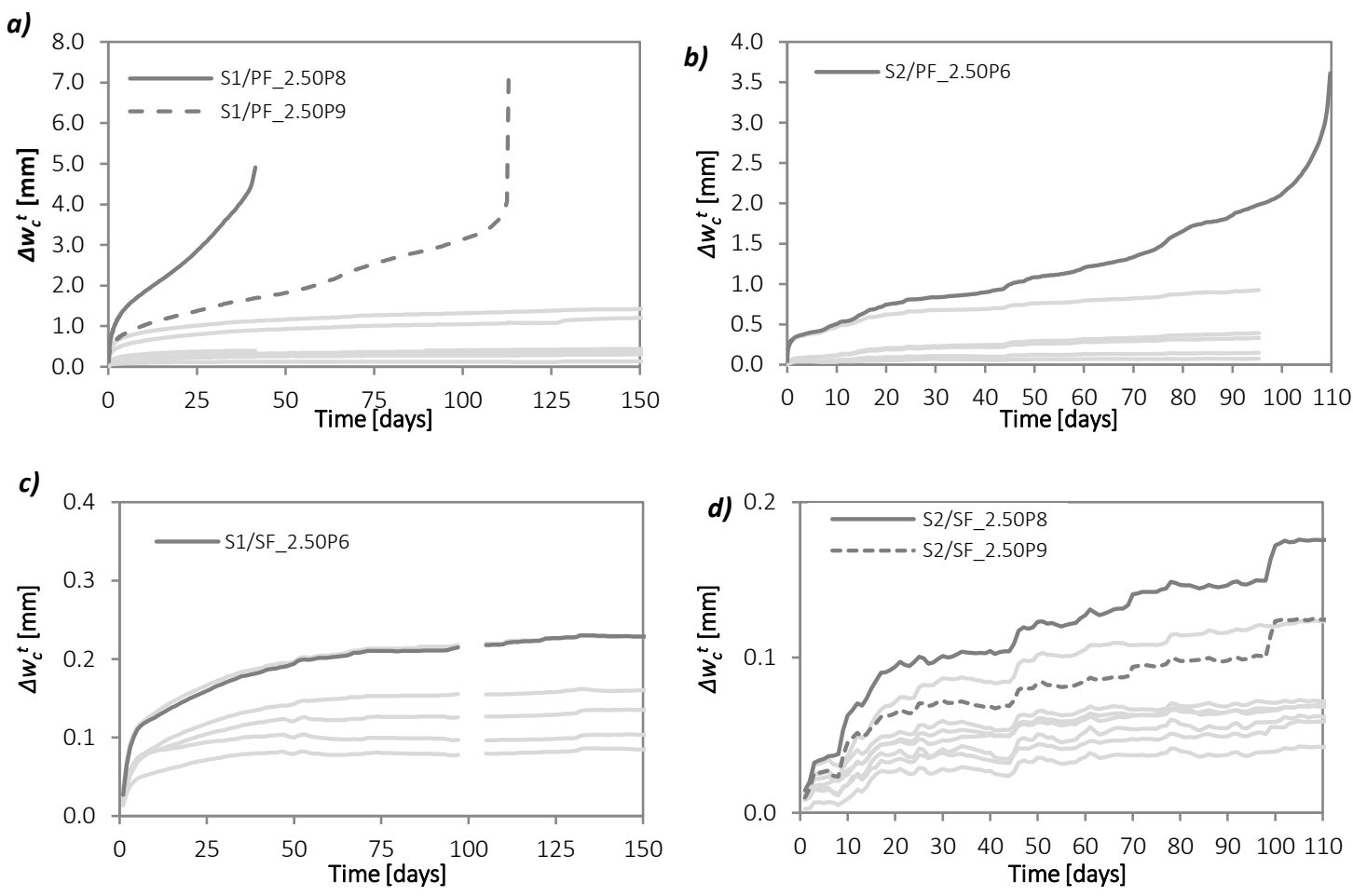

Figure 10 - Evolution of $\Delta w_{c}^{t}$ over time for specimens with $w_{p}^{f}$ of $2.50 \mathrm{~mm}:$ PFRC ( $a$ and $\left.b\right)$ and SFRC (c and d)
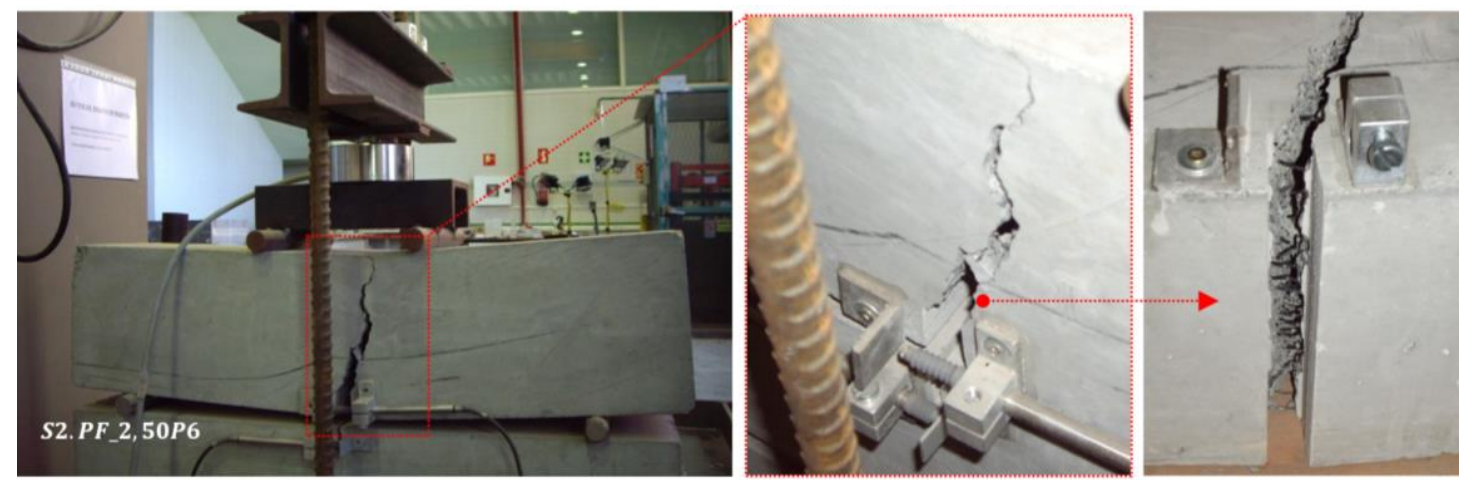

Figure 11 - Failure of S2/PF_2.50P6 affected by tertiary creep

The difference of creep behaviour between $w_{p}^{f}$ of $0.25 \mathrm{~mm}$ or $1.50 \mathrm{~mm}$ and $w_{p}^{f}$ of $2.50 \mathrm{~mm}$ raises several questions. One of them is regarding the representativeness of the test condition in comparison with reality. Despite the critical performance of PFRC beams with $w_{p}^{f}$ of $2.50 \mathrm{~mm}$, it is important to remark that such a big crack opening is not representative of the typical situation of most elements in SLS. In fact, structural elements with pre-crack openings of $2.50 \mathrm{~mm}$ are not likely to be kept in service for long periods of time without any precautionary reparation measured to restore the original state. Therefore, the assumption of a sustained load is not likely to occur in practice, being more realistic the behavior depicted in section 4.2 for elements with $w_{p}^{f}$ of 0.25 $\mathrm{mm}$. However, special attention should be payed to elements not visible in which the severe cracking and the high deformation would not be easily detected.

Another underlying question is related with the importance of limiting the maximum allowable crack opening throughout the service life of the structural element. In this matter, the results from the experimental program suggest that especially in PFRC elements it is necessary to limit the maximum crack opening to reduce the risk of failure due to tertiary creep. 


\section{4- Creep coefficient}

The time-dependent crack width $\left(w_{c}^{t}\right)$ of each specimen progressively increased throughout the creep tests, varying in accordance with the value of the pre-crack width and the load-level. However, the inherent scatter of the creep test and the material [45-47] together with the fact that each specimen was under slightly different load levels (see Table 4), hinders any direct quantitative comparison of the results.

The analysis of the creep coefficient is proposed to overcome these drawbacks [48]. The creep coefficient for an instant $t$ is defined as the ratio between the deformation due to creep and the elastic deformation. However, when deformation is not directly measured, the creep coefficient may be determined by means of the crack width or the deflection, as reported in [20], [25] and [33]. Therefore, for the purpose of this research, the creep coefficient $(\varphi(t))$ at the time $\mathrm{j}$ was calculated as the ratio between the crack width due to creep at the time $\mathrm{j}\left(w_{c}^{j}\right)$ and the initial crack width measured immediately after applying the load in the creep test $\left(w_{c}^{o}\right)$. The equation for the assessment of $\varphi(t)$ is shown in shown in eq. 1 .

$$
\varphi(t)=\frac{\Delta w_{c}^{t}}{w_{c}^{o}}
$$

The evolution of $\varphi(t)$ for both environment conditions for PFRC and SFRC specimens is presented in Fig. 12.
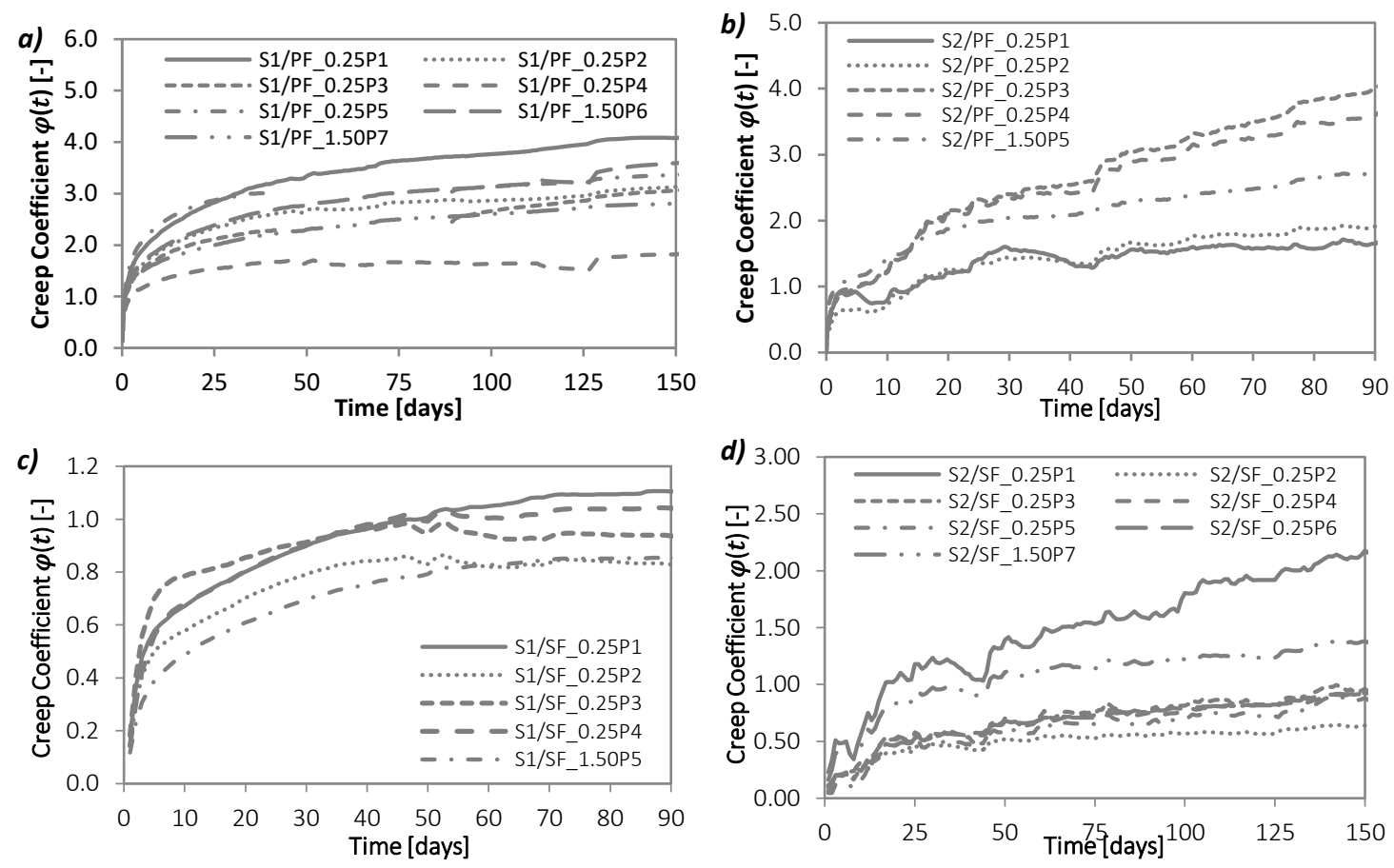

Figure 12 - Evolution of $\varphi(t)$ for beams with PFRC ( $a$ and $b$ ) and SFRC (c and d) for $w_{p}^{f}$ of $0.25 \mathrm{~mm}$ and $1.50 \mathrm{~mm}$ 
Taking $\mathrm{t}=90$ days as reference, a $\varphi(t=90)$ value between 1.5 and 3.5 was reached for all specimens with PFRC, regardless of the environmental condition. Following the trend indicated in previous sections for the $\Delta w_{c}^{t}$, the creep coefficient stabilized within several days in specimens subjected to $\mathrm{S} 1$, whereas it increased monotonously over time in specimens subjected to $\mathrm{S} 2$.

The same trend was observed for the specimens with SFRC. However, the latter presented significantly lower $\varphi(t)$ than the equivalent specimens with PFRC. Notice that the $\varphi(t=90)$ for SFRC beams subjected to S1 ranged between 1.0 and 1.4, while for S2 this parameter ranged between 0.6 and approximately 2.1 .

During secondary creep, the range of $\varphi(t=90)$ was not significantly affected by $w_{p}^{f}$ for both types of FRC. Indeed, similar values of $\varphi(t)$ were achieved for $w_{p}^{f}$ of $0.25 \mathrm{~mm}$ and $1.50 \mathrm{~mm}$, considering the same environmental condition. This outcome may have a positive repercussion in the philosophy adopted to account for the creep of FRC in the design. It suggests that the creep coefficient could be assumed similar regarded that the initial crack opening is limited. For equivalent conditions, specimens with PFRC experienced values of $\varphi(t)$ around twice as big as those with SFRC.

\section{5-Conclusion}

The creep phenomenon in cracked flexural elements of FRC is a potentially harmful phenomenon which should not be overlooked. The most relevant conclusions from this study are described below.

- The increase of crack width caused by creep was between 6 and 10 times bigger for PFRC beams in comparison with equivalent beams with SFRC. This may be the result of a more intense damage of the fiber-matrix interface for the same pre-crack opening in the case of PFRC. It may also be caused by the own creep of the plastic fiber at an individual level.

- The creep coefficients obtained for PFRC at 90 days were between 1.5 and 3.5. At similar loading levels and for $w_{p}^{f}$ smaller than $1.50 \mathrm{~mm}$, cracked PFRC can be expected to present creep coefficients around twice of those found for equivalent SFRC elements. Until this age and for both types of fiber, the creep coefficient was not affected by the pre-cracking value $\left(w_{p}^{f}\right)$. This suggests that a reference creep coefficient could be applied in the design regarded that the crack opening is limited.

- For large pre-cracking widths $(2.5 \mathrm{~mm})$, the plastic fiber-matrix interaction was severely damaged. Although the fibers did not break in any of the cases under analysis, the increase of the crack width over the creep tests favored fiber pull out and depleted progressively the tensile strength provided by the fibers, which caused additional increases of the crack opening. This generated an accumulation effect, an acceleration of the creep rate and, ultimately, the failure of beams with PFRC, which showed tertiary creep.

These observations in no way mean that plastic fibers cannot be used for the partial or total replacement of conventional reinforcement. To safely use the material, the additional creep deformation expected should be considered in the design. Moreover, it should be ensured that creep behavior beyond the stage of secondary creep will not take place during the service life. In order to meet this requirement, crack opening and load level limitations should be defined for the design of FRC structures. This is especially important for PFRC since it is more likely to present tertiary creep. For that purpose, additional studies should be conducted about the critical pre-crack opening that may lead to tertiary creep in the case of PFRC elements. 


\section{Acknowledgments}

The authors of this paper wish to show their gratitude for the economic support received through the Research Project BIA2010-17478: Construction Processes by means of Fiber Reinforced Concretes. The authors thank the company ESCOFET S.A. for their collaboration in the development of the experimental program. The first author acknowledges the PDJ grant provided by the Departament d'Universitats, Recerca i Societat de la Informació de la Generalitat de Catalunya.

\section{References}

[1] M. di Prisco, G. Plizzari, and L. Vandewalle, "Fibre reinforced concrete: new design perspectives," Mater. Struct., vol. 42, no. 9, pp. 1261-1281, Sep. 2009.

[2] J. C. Walraven, "High performance fiber reinforced concrete: progress in knowledge and design codes," Mater. Struct., vol. 42, no. 9, pp. 1247-1260, Oct. 2009.

[3] P. Pujadas, A. Blanco, S. H. P. Cavalaro, A. De La Fuente, and A. Aguado, "Multidirectional double punch test to assess the post-cracking behaviour and fibre orientation of FRC," Constr. Build. Mater., vol. 58, pp. 214-224, 2014.

[4] M. G. Alberti, a. Enfedaque, J. C. Gálvez, M. F. Cánovas, and I. R. Osorio, "Polyolefin fiberreinforced concrete enhanced with steel-hooked fibers in low proportions," Mater. Des., vol. 60, pp. 57-65, 2014.

[5] M. G. Alberti, A. Enfedaque, and J. C. Gálvez, "Comparison between polyolefin fibre reinforced vibrated conventional concrete and self-compacting concrete," Constr. Build. Mater., vol. 85, pp. 182-194, 2015.

[6] L. Vandewalle, "Cracking behaviour of concrete beams reinforced with a combination of ordinary reinforcement and steel fibers," vol. 33, no. April, pp. 164-170, 2000.

[7] P. Pujadas, A. Blanco, A. Fuente, and A. Aguado, "Cracking behavior of FRC slabs with traditional reinforcement," Mater. Struct., vol. 45, no. 5, pp. 707-725, Oct. 2011.

[8] L. Liao, A. de la Fuente, S. Cavalaro, and A. Aguado, "Design procedure and experimental study on fibre reinforced concrete segmental rings for vertical shafts," Mater. Des., vol. 92, pp. 590-601, 2016.

[9] E. V. Sarmiento, M. R. Geiker, and T. Kanstad, "Influence of fibre distribution and orientation on the flexural behaviour of beams cast from flowable hybrid polymer-steel FRC," Constr. Build. Mater., vol. 109, pp. 166-176, 2016.

[10] A. Blanco, P. Pujadas, A. de la Fuente, S. Cavalaro, and A. Aguado, "Influence of the type of Fiber on the structural response and design of FRC slabs," J. Struct. Eng., 2016.

[11] S. Yin, R. Tuladhar, F. Shi, M. Combe, T. Collister, and N. Sivakugan, "Use of macro plastic fibres in concrete: A review," Constr. Build. Mater., vol. 93, pp. 180-188, 2015.

[12] N. Buratti, C. Mazzotti, and M. Savoia, "Post-cracking behaviour of steel and macro-synthetic fibre-reinforced concretes," Constr. Build. Mater., vol. 25, no. 5, pp. 2713-2722, 2011.

[13] P. Pujadas, A. Blanco, S. Cavalaro, and A. Aguado, "Plastic fibres as the only reinforcement for flat suspended slabs: Experimental investigation and numerical simulation," Constr. Build. Mater., vol. 57, pp. 92-104, Apr. 2014.

[14] P. Pujadas, a. Blanco, S. H. P. Cavalaro, a. Aguado, S. Grünewald, K. Blom, and J. C. Walraven, "Plastic fibres as the only reinforcement for flat suspended slabs: Parametric study and design considerations," Constr. Build. Mater., vol. 70, pp. 88-96, Nov. 2014.

[15] P. Pujadas, A. Blanco, S. Cavalaro, A. de la Fuente, and A. Aguado, "Fibre distribution in macroplastic fibre reinforced concrete slab-panels," Constr. Build. Mater., vol. 64, pp. 496-503, Aug. 2014.

[16] A. Conforti, F. Minelli, A. Tinini, and G. a. Plizzari, "Influence of polypropylene fibre 
reinforcement and width-to-effective depth ratio in wide-shallow beams," Eng. Struct., vol. 88, pp. $12-21,2015$.

[17] G. Tiberti, A. Conforti, and G. a. Plizzari, "Precast segments under TBM hydraulic jacks: Experimental investigation on the local splitting behavior," Tunn. Undergr. Sp. Technol., vol. 50, pp. 438-450, 2015.

[18] W. P. Boshoff, V. Mechtcherine, and G. P. a. G. van Zijl, "Characterising the time-dependant behaviour on the single fibre level of SHCC: Part 1: Mechanism of fibre pull-out creep," Cem. Concr. Res., vol. 39, no. 9, pp. 779-786, Sep. 2009.

[19] G. Zhao, M. di Prisco, and L. Vandewalle, "Experimental investigation on uniaxial tensile creep behavior of cracked steel fiber reinforced concrete Experimental investigation on uniaxial tensile creep behavior of cracked steel fiber reinforced concrete," Mater. Struct., pp. 0-11, 2014.

[20] A. Abrishambaf, J. A. O. Barros, and V. M. C. F. Cunha, "Time-dependent flexural behaviour of cracked steel fibre reinforced self-compacting concrete panels," Cem. Concr. Res., vol. 72, pp. 21$36,2015$.

[21] J.L. Granju, P. Rossi, G. Chanvillard, B. Mesureur, A. Turatsinze, H. Farhat, C. Boulay, J.J. Serrano, P. Fakhri, O. Roque, And P. Rivillon, "Delayed behaviour of cracked SFRC beams," pp. $511-520,2000$

[22] A. J. Babafemi and W. P. Boshoff, "Tensile creep of macro-synthetic fibre reinforced concrete (MSFRC) under uni-axial tensile loading,” Cem. Concr. Compos., vol. 55, pp. 62-69, Jan. 2015.

[23] E. S. Bernard, "Influence of fiber type on creep deformation of cracked fiber-reinforced shotcrete panels," ACI Mater. J., vol. 107, no. 107, pp. 474-480, 2010.

[24] R. L. Zerbino and B. E. Barragán, "Long-term behavior of cracked steel fiber-reinforced concrete beams under sustained loading," ACI Mater. J., vol. 109, no. 109, pp. 215-224, 2012.

[25] N. Buratti and C. Mazzotti, "Experimental tests on the effect of temperature on the long-term behaviour of macrosynthetic Fibre Reinforced Concretes," Constr. Build. Mater., vol. 95, pp. 133$142,2015$.

[26] G. Liu, X., Huang, Y., Deng, C., Wang, X., Tong, W., Liu, Y., Huang, J., Yang, Q., Liao, X. and Li, "Study on the Creep Behavior of Polypropylene Xiaolin," Polym. Eng. Sci., vol. 49, no. 7, pp. $1375-1382,2009$.

[27] W. P. Boshoff and C. J. Adendorff, "Effect of sustained tensile loading on SHCC crack widths," Cem. Concr. Compos., vol. 37, no. 1, pp. 119-125, 2013.

[28] W. Kusterle, "Viscous material behavior of solids- creep of polymer fiber reinforced concrete." $p$. 5, 2009.

[29] S. Kurtz and P. Balaguru, "Postcrack creep of polymeric fiber-reinforced concrete in flexure," Cem. Concr. Res., vol. 30, no. July 1999, pp. 183-190, 2000.

[30] K. H. Tan, P. Paramasivam, and K. C. Tan, "Instantaneous and long-term deflections of steel fiber reinforced concrete beams," ACI Struct. J., vol. 91, no. 91, pp. 384-393, 1994.

[31] K. H. Tan and M. K. Saha, "Ten-year study on steel fiber-reinforced concrete beams under sustained loads," ACI Struct. J., vol. 102, no. 102, pp. 472-480, 2005.

[32] K. Tan, P. Paramasivam, and K. Tan, "Creep and shrinkage deflections of RC beams with steel fibers," J. Mater. Civ. ..., vol. 6, no. 4, 1994.

[33] S. E. Arango, P. Serna, J. R. Martí-Vargas, and E. García-Taengua, "A Test Method to Characterize Flexural Creep Behaviour of Pre-cracked FRC Specimens,” Exp. Mech., vol. 52, no. 8, pp. 10671078, Oct. 2011.

[34] E. García-Taengua, S. Arango, J. R. Martí-Vargas, and P. Serna, "Flexural creep of steel fiber reinforced concrete in the cracked state," Constr. Build. Mater., vol. 65, pp. 321-329, Aug. 2014.

[35] J. MacKay and J. F. Trottier, "Post-crack creep behavior of steel and synthetic FRC under flexural loading," in Shotcrete: More Engineering Developments, 2004, pp. 183-192. 
[36] T. Bast, A. Eder, F. Regensburg, and F. Bauingenieurwesen, "Untersuchungen zum Langzeitverhalten von Faserbetonen unter Biegezugbeanspruchung - ein Zwischenbericht," no. Bild 2, pp. 32-35.

[37] H. Klinkert, J. Rosenbusch, and M. Teutsch, "Long Time Behaviour and Influence of the Height of Steel Fibre Reinforced Concrete Members," 2002.

[38] R. Gettu, "Test and Design Methods for Steel Fibre Reinforced Concrete-Creep in the Post-Cracked Region," 2002.

[39] J. MacKay, "Behaviour of steel and synthetic fibre reinforced concrete under flexural creep loading.," Dalhousie University, Halifax., 2002.

[40] Jonh T. Cochrane, "Flexural Creep Behaviour of fibre Reinforced concrete under high Temperatures,” Dalhousie University, Halifax., 2003.

[41] O. Bernard, F.-J. Ulm, and E. Lemarchand, "A multiscale micromechanics-hydration model for the early-age elastic properties of cement-based materials," Cem. Concr. Res., vol. 33, no. 9, pp. 12931309, Sep. 2003.

[42] K. Kovler, "Interdependence of Creep and Shrinkage for Concrete under Tension," J. Mater. Civ. Eng., vol. 7, no. 2, pp. 96-101, 1995.

[43] Z. P. Bazant, "Drying creep of concrete:constitutive model and new experiments separating its mechanisms.," Mater. Struct., vol. 27, pp. 3-14, 1994.

[44] W. P. Boshoff, V. Mechtcherine, and G. P. a. G. van Zijl, "Characterising the time-dependant behaviour on the single fibre level of SHCC: Part 2: The rate effects on fibre pull-out tests," Cem. Concr. Res., vol. 39, no. 9, pp. 787-797, Sep. 2009.

[45] S. H. P. Cavalaro and a. Aguado, "Intrinsic scatter of FRC: an alternative philosophy to estimate characteristic values,” Mater. Struct., no. Cv, 2014.

[46] Buratti, N., \& Mazzotti, C. (2017). Creep Testing Methodologies and Results Interpretation. In Creep Behaviour in Cracked Sections of Fibre Reinforced Concrete (pp. 13-24). Springer, Dordrecht.

[47] Gettu, R., Zerbino, R., \& Jose, S. (2017). Factors Influencing Creep of Cracked Fibre Reinforced Concrete: What We Think We Know \& What We Do Not Know. In Creep Behaviour in Cracked Sections of Fibre Reinforced Concrete (pp. 3-12). Springer, Dordrecht.

[48] Pujadas, P., Blanco, A., Cavalaro, S. H., de la Fuente, A., \& Aguado, A. (2017). Flexural Postcracking Creep Behaviour of Macro-synthetic and Steel Fiber Reinforced Concrete. In Creep Behaviour in Cracked Sections of Fibre Reinforced Concrete (pp. 77-87). Springer, Dordrecht. 